\title{
Mal-uniformity Distribution of Fluid Flow through Corrugated Channel of Brazed Plate Heat Exchanger
}

\author{
OMuh. Anis Mustaghfirin ${ }^{1,2}$, Akio Miyara ${ }^{1}$ \\ ${ }^{1}$ Department of Mechanical Engineering, Saga University, Japan \\ ${ }^{2}$ Department of Marine Engineering, Ship Building State Polytechnic of Surabaya, Indonesia
}

Keywords: plate heat exchanger, corrugate, mal-uniformity, distribution

\begin{abstract}
The mal-uniformity phenomenon of plate heat exchanger has not disclosed clearly. This work enhances the 3D modeling of corrugate channels of brazed plate heat exchanger completely, covering geometry in inlet and outlet distributor zone. The full acrylic corrugated channel is as test section used as validator, tested in two-phase flow mode in order to track the flow distribution clearly. It is revealed that the mal-uniformity is generated by geometry of inlet and outlet distributor zone for single phase flow and it tend to be promoted by flow pattern, buoyancy effect as well as geometry of inlet and outlet distributor zone for two-phase flow.
\end{abstract}

\section{Introduction}

There are several works about plate heat exchanger including brazed type, experimentally and or modeling. Unfortunately, the mal-uniformity phenomenon has not disclosed clearly. The most of existing study was analyzed the macroscopic impacts of flow through plate heat exchanger channel via measuring pressure, temperature and flow at their inlet and outlet ports, Macin et al. [1]. Some works have investigated the flow distribution by using sight windows, but the sighting is limited on corrugate channel zone and is not in the inlet and outlet distributor zone, Nilpueng et al. [2]. Moreover the results are presented as $2 \mathrm{D}$ video file. Consequently, the detail information about flow distribution still has not adequate yet. The modeling study is an attractive option to reveal the mal-uniformity distribution phenomenon, and that had been done, Han et al. [3]. Again, the analysis tends to lack, due to complicated geometry in inlet and outlet distributor zone which has not been modeled properly. This work had enhanced the brazed plate heat exchanger model closed to test section made by acrylic, molded equal to real plate heat exchanger surface. The test section had been tested in two-phase flow mode in order to track the flow distribution clearly. The integration between complete modeling and experimental reveals cause of mal-uniformity distribution clearly.

\section{Modeling and experimental setup}

The original plate of brazed plate heat exchanger, Fig. 1, is derived as test section made from acrylic molded equally, Fig. 2. Also, it is modeled similarly, as Fig.3. Air and water are fed to two-phase generator 5 to develop various flow patterns. Each flow rate is regulated by valve $3 a$ and $3 b$ as well as fixed by rotameter $4 a$ and $4 b$. The generated flow pattern is fed to corrugated acrylic channel 6 , as test section, observed flow distribution using high speed camera 10 and discharged to air water separator 7. The actual flow rate of each air and water is measured using bath flow meter 8 and 9 with maximum errors up to $0.393 \%$ and $0.106 \%$ respectively.

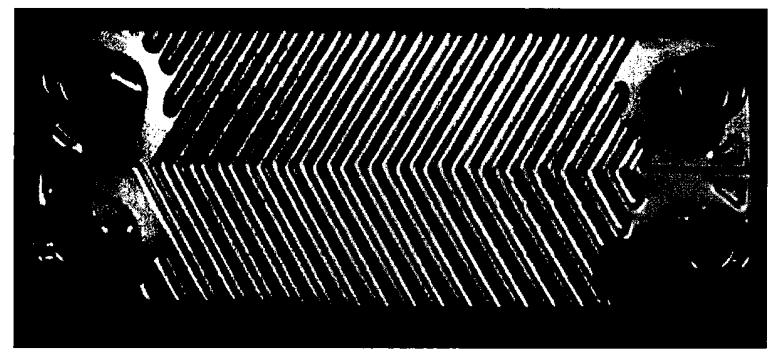

Fig.1 Original Plate of Brazed Plate Heat Exchanger

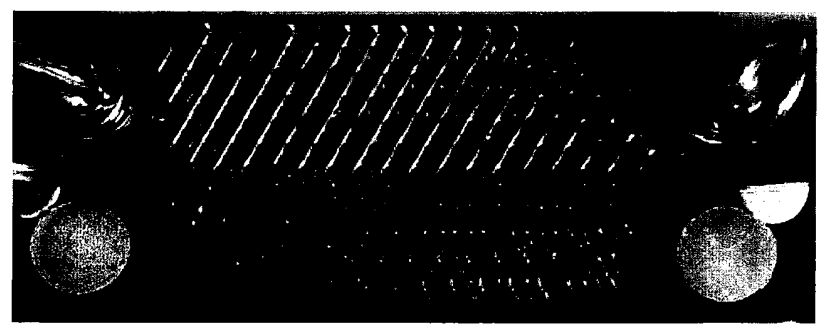

Fig.2 Molded Acrilic Test Section

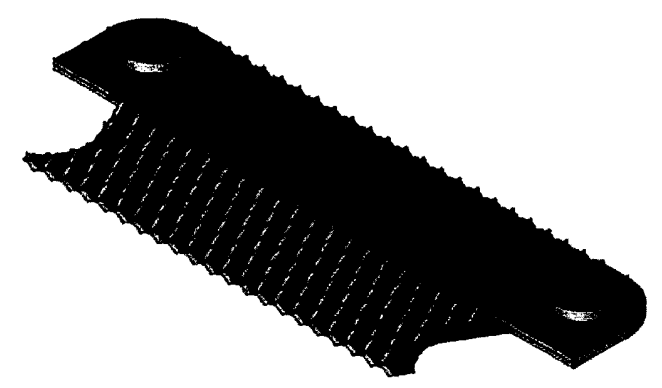

Fig.3 Full Test Section Model

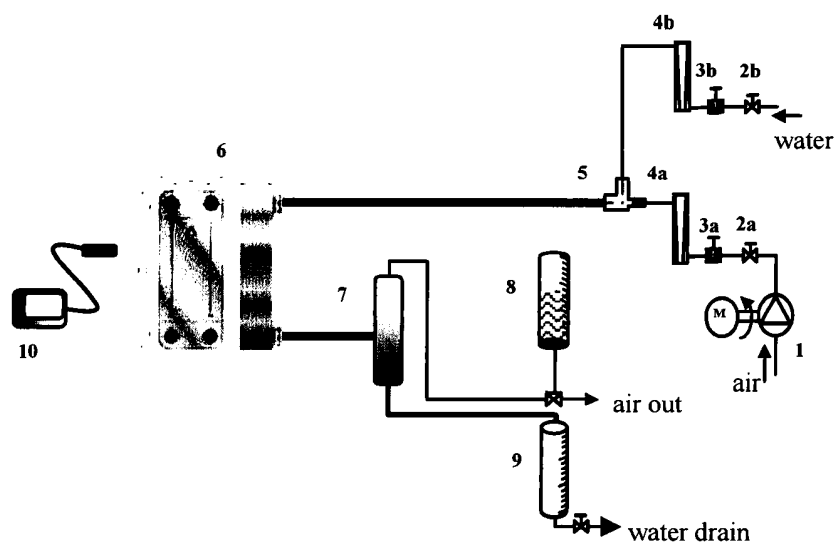

Fig.4 Experimental Setup 


\section{Result and Discussions}

The boundary conditions are; constant water inlet velocity: $0.2 \mathrm{~m} / \mathrm{s}$, equivalent to total volume flow rate $2.265 \mathrm{~L} / \mathrm{min}$, at $26.85^{\circ} \mathrm{C}$ and constant wall surface temperature $0^{\circ} \mathrm{C}$. The model was run on steady state mode resulting velocity distribution Fig.5, temperature distribution Fig.6 and pressure distribution Fig. 7. All figures are about center plane of corrugate channel of brazed plate heat exchanger model.

Fig. 5, mal-uniformity is occurred, since the highset velocity is ditributed along edge closed to inlet and outlet manifold, the moderate velocity is distributed along edge
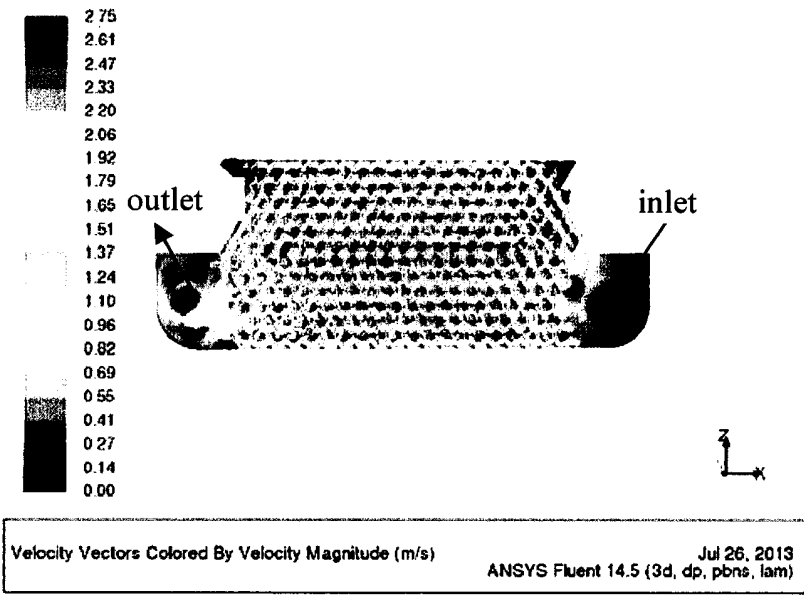

Fig.5 Velocity Distribution
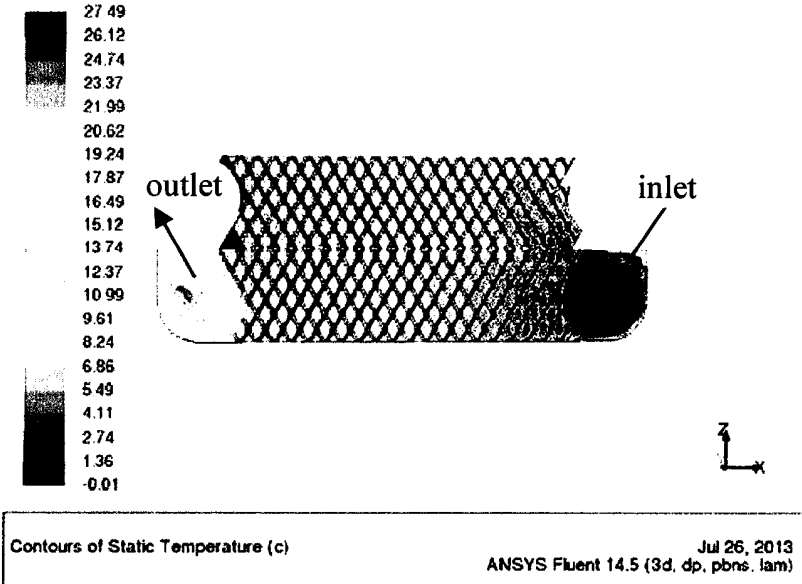

Fig.6 Temperature Distribution
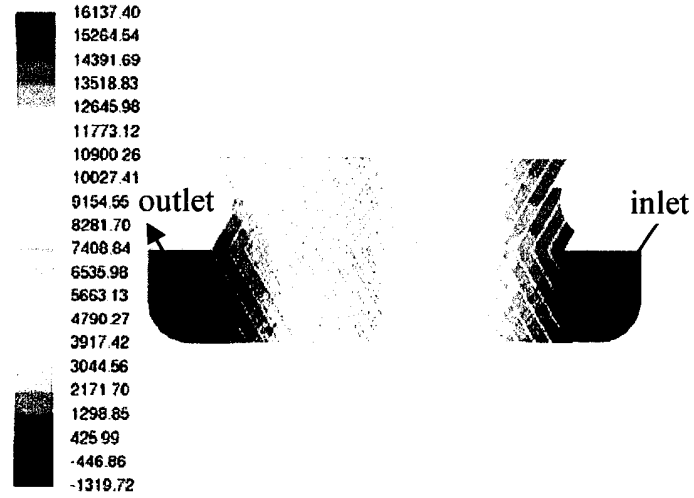

Contours of Static Pressure (pascal) ANSYS Fivent 14.5 (30, Jul 26.2013

Fig.7 Pressure Distribution away from inlet and outlet manifold. The lowest velocity is distributed in center line of plate or in intersection of corrugated heringbone zone. The mal-uniformity tends to be promoted by geometry of inlet and outlet distributor zone, formed by attached of couple plates. Also, it is due to parallel inlet outlet configuration. Potensially, the cross inlet outlet configuration as well as modifiying their surface geometry shall enhance uniformity flow distribution .

In single flow, though the velocity distribution ununiform, the temperture distribution, Fig. 6 and pressure distribution, Fig. 7 are still closed to uniform. Meanwhile, the pressure drop tend to significanly high in inlet port, due to changing velocity vector orientation from horizontally inlet tube to vertically corrugated channel.

The Fig. 8. is two-phase flow distribution through test section.

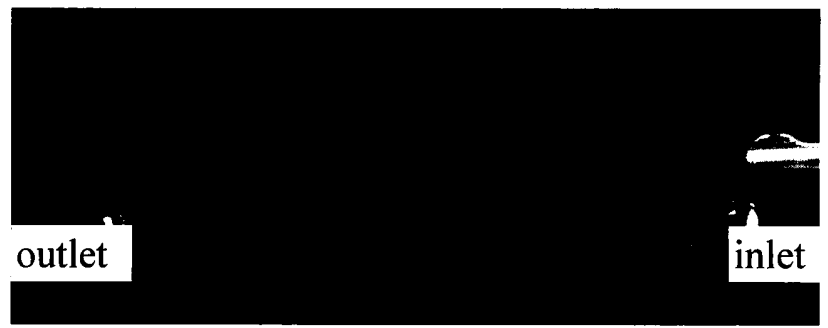

Fig.8 Phase Distribution

The inlet tube boundary conditions are; the air superficial velocity $j_{G}: 0.28 \mathrm{~m} / \mathrm{s}$ and the water supervicial velocity $j_{L}$ : $0.08 \mathrm{~m} / \mathrm{s}$. Equivalent with total air flow rate, $Q_{G}: 0.789$ $\mathrm{L} / \mathrm{min}$ and total water The flow rate, $Q_{L}: 0.676 \mathrm{~L} / \mathrm{min}$. The flow direction is verticaly downward and depicted as towards negative $x$ axis. It is revealed that the two phase flow distribution is correspond with single phase velocity distribution, in which the air/bubble tend to distribute more unevenly along corrugate channel. The bubble along edge, away from inlet outlet port is more than it along edge, adjacent inlet outlet port. While, in the in center line, in the intersection of heringbone zone, the air/bubble is more limited. This mal-uniformity tends to be promoted by channel geometry, flow pattern and bouyancy effect

\section{Conclusions}

The geometry of inlet and outlet distributor zone of corrugated brazed plate heat exchanger primarily promotes mal-uniformity for single phase flow moreover for twophase flow. More unevenly flow distribution of two phase flow is promoted by additional effect of flow pattern and buoyancy.

\section{References}

1. S. Mancin, D.D. Col, L. Rossetto, R32 partial condensation inside a brazed plate heat exchanger, Int. Journal of Refrigeration, 36, 601-611 (2013).

2. K. Nilpueng, S. Wongwises, Two-phase gas-liquid flow characteristics inside a plate heat exchanger, Experimental Thermal and Fluid Science, 34, 12171229 (2010).

3. X.H. Han, L.Q. Cui, S.J. Chen, G.M. Chen, Q. Wang, A numerical and experimental study of chevron, corrugated-plate heat exchangers, International Communications in Heat and Mass Transfer, 37, 1008-1014 (2010). 